Reprod. Nutr. Dévelop., 1987, 27 (1 B), 211-212.

\title{
Influence de l'âge et de la race sur la capacité d'ingestion des femelles bovines
}

J. AGABRIEL, P. D'HOUR, M. PETIT

Laboratoire de l'Elevage Bovin

I.N.R.A. Theix, 63122 Ceyrat.

I.N.R.A. Domaine Expérimental, 15190 Condat

Summary. The same hays were given ad libitum to 1- or 2-year old heifers and cows of 3 different breeds : one dairy breed, Friesian, and two beef breeds, Salers and Limousine. Feed intake increased with live weight raised to power 0.91 and depended significantly on age variations around the first year. It also depended on breed as follows: Friesian > Salers > Limousine, specially for one year old heifers. This could result from the different rumen development induced by various managements and weaning ages.

La quantité de matière sèche volontairement ingérée, mesurée dans de nombreux essais où les animaux étaient nourris à volonté, a permis d'établir les valeurs de la capacité d'ingestion des bovins en croissance ou à l'engrais. II avait été retenu (Geay et al., 1978) qu'elle variait peu avec l'âge et le sexe lorsqu'elle était exprimée par $\mathrm{kg}$ de poids métabolique $\left(\mathrm{P}^{0,75}\right)$, et dépendait essentiellement du génotype ou de l'état d'engraissement (Micol et Béranger, 1981).

Nous apportons ici les résultats de comparaisons simultanées de la capacité d'ingestion de femelles de trois races au cours de la croissance $(<500 \mathrm{~g} / \mathrm{j}$ ) et à l'âge adulte.

Matériel et méthodes. Sur le domaine I.N.R.A. de Marcenat, les capacités d'ingestion de 96 génisses de 1 an (351 jours \pm 51 ), de 48 génisses de 2 ans (720 jours \pm 43), des races Salers (SA), Limousine (LI) et Pie Noire (PN) et de 42 vaches adultes taries en gestation ( $8^{e}$ mois) des mêmes races, ont été comparées simultanément. Les mesures ont été faites durant 4 à 5 semaines après une période de 2 semaines : les animaux des trois classes d'âge recevaient un même foin de prairie naturelle ad libitum, $300 \mathrm{~g} / \mathrm{j}$ de tourteau d'arachide ou de soja, et 100 à $150 \mathrm{~g} / \mathrm{j}$ d'un mélange de minéraux et vitamines.

Les quantités journalières ingérées ont été mesurées individuellement ; les animaux ont été pesés 2 à 4 fois par période. Les résultats de quantités de matières sèches de foin ingérées ont été soumis par classe d'âge à une analyse de variance (race, foin, poids et/ou âge).

Résultats et discussion. Toutes races confondues les quantités de foin ingérées doublent approximativement de un an à l'âge adulte (voir tabl.). Elles varient ainsi proportionnellement au poids vif élevé à la puissance $0,91( \pm 0,02)$ sans interaction avec la race. Pour mieux cerner les variations de l'ingestion strictement liées à l'âge, nous avons testé, intra-classe d'âge (1 et 2 ans) et par régression linéaire, les influences respectives de l'âge (variable à l'extrême de 180 jours) et du poids. Pour les génisses de deux ans, seul le poids a eu un effet significatif sur les quantités de foin ingérées $(+11 \mathrm{~g} / \mathrm{kg}$ poids supplémentaire). Par contre pour les génisses de 1 an les quantités de foin ingérées augmentent significativement soit avec l'âge $(+8,1 \mathrm{~g} /$ jour d'âge supplémentaire $)$ soit avec le poids $(+9,0 \mathrm{~g} / \mathrm{kg}$ de poids supplémentaire). La liaison entre poids et âge étant faible, nous avons aussi introduit ces deux variables simultanément dans le modèle d'analyse : le poids 
conserve la plus forte influence $(+6,5 \mathrm{~g} / \mathrm{kg}$ supplémentaire) mais celle de l'âge est presque significative $(+3,3 \mathrm{~g} /$ jour supplémentaire $)$.

TABL. 1. - Influence de l'âge de la race sur les quantités de matière sèche (MS) de foin ingérées

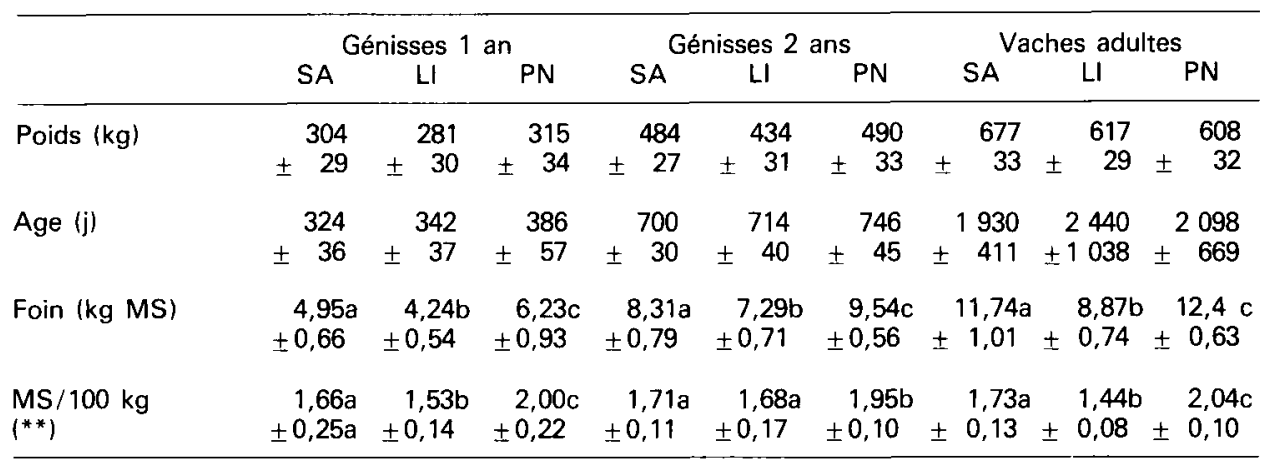

Intragénération : lettres différentes : $P<0,01 ;{ }^{*}$ : Valeurs rapportées au même âge, 360 jours, pour les génisses de 1 an.

Ces valeurs permettent de corriger les quantités ingérées mesurées pour comparer les races exactement au même âge. Les importants écarts observés (Pie Noires $>$ Salers $>$ Limousines) sont proches de ceux mentionnées par Geay et al. (1978) sur des mâles en croissance rapide. Ils sont tous significatifs à 1 an $(p<0,01)$, mais tendent à s'atténuer sur les génisses de 2 ans notamment entre les Salers et les Limousines, contrairement à ce qu'ont constaté Thiessen et al. (1984) sur des races britanniques. Ces écarts entre races se confirment cependant sur les vaches adultes, mais ils peuvent alors être accentués par des différences d'état d'engraissement. Sur les génisses de 1 an ils peuvent aussi, pour partie, être liés à des modes d'élevage différents; en particulier les quantités ingérées plus élevées chez les génisses Pie Noires ont peut-être été accentuées par le sevrage précoce à 10 semaines qui induit un développement plus précoce du rumen. Entre Salers et Limousines, élevées au pis jusqu'à 9 mois, l'écart pourrait plutôt résulter d'une différence dans le développement du rumen au même âge.

Du fait des très faibles quantités d'aliments concentrés distribuées, ces résultats ne serait pas modifiés si nous les avions exprimés en matières sèches totales ingérées.

Geay Y., Robelin J., Béranger C., Micol D., 1978. In Alimentation des Ruminants, 297-381, éd. I.N.R.A. Publ., 78000 Versailles.

Micol D., Béranger C., 1981. Bull. Techn. CRZV Theix I.N.R.A., 44, 23-31.

Thiessen R. B., Hnizdo E., Maxwell D. A., Gibson D., Taylor ST C. S., 1984. Anim. Prod., 38, $323-$ 340 . 